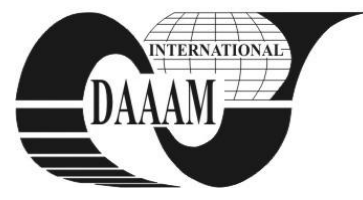

\title{
CONSIDERATIONS ABOUT THE STRUCTURE OF CALIBRATED COLD DRAWN STEEL BARS PREPARED THROUGH THE ECOTECHNOLOGY OF SANDBLASTING
}

\author{
MOTOMANCEA, I[rina] L[elia] \& MOTOMANCEA, A[drian]
}

\begin{abstract}
This survey was carried out to the end of experimenting a new technological process for preparing precast steel products for steel drawing, respectively bead blasting. The objects of study were circular steel bars and rectangular steel platbands, cold drawn, for which the hardness $\mathrm{HV}_{02}$ was determined. Also, these samples were microscopically observed, monitoring the orientation and sizing of grains resulted from plastic deformation, in the central areas of the sections as well as in marginal areas.

Key words: steel bar, blasting, hardness, optical microscopy
\end{abstract}

\section{INTRODUCTION}

A special importance in the technological process of cold drawing of bars is held by the preparation of materials, including the removal of oxides, aimed to achieve a flawless surface as well as to maintain lubrication while drawing.

The classical preparation method is chemical pickling, made by treating the bars in sulfuric acid or hydrochloric acid bath, resulting in dissolving of iron oxides.

Due to significant environmental threats incurred by the classical technology (caused by the neutralization of acid solutions, chemical prickling generating fluid wastes of used acid $\mathrm{HCl}$ or $\mathrm{H} 2 \mathrm{SO} 4)$ and the increasing demands for cold drawn bars (most cold drawing plants in Romania were closed exactly due to this obsolete technology) we have developed an ecological technology for bar drawing, where the removal of iron scales is achieved using bead blasting.

This paper is intended to determine the effects of cold drawing deformation on the mechanical strength properties (HV02 hardness) of metallic materials (determining and comparing the micro-hardness in central areas compared to peripheral areas of the processed product) as well as of altering the structure of the precast product, by microscopically examining the samples (orientation and sizing of grains generated by the plastic deformation, in central areas as well as in peripheral areas), when the product preparation (removal of oxides from the outer side of bars) is achieved mechanically, through bead blasting (Oprea, 1978)

\section{CONTENTS OF PAPER}

We worked with samples represented by cold drawn bars processed on the "Chain drawing bench" 50 tof. present in the economic agent's production department. The experiments used two types of precast products: hot laminated bar $\varnothing 42$, material OLC45 and hot laminated rectangular platband 20x14mm, material OLC15.

Reduction to circular steel bar was from $\varnothing 42$ to $\varnothing 40$, and in the case of platband several successive reductions were made, from $20 \times 14 \mathrm{~mm}$ to $20 \times 12 \mathrm{~mm}$. These analyses were carried out within the Metallographic Testing Lab LAMET within the Polytechnic University in Bucharest. Samples were taken from the steel bars as well as from the platbands, after reduction.
Steel samples underwent hardness test as well as microscopic analysis.

For hardness test. Devices used: MicroHardnessmeter SHIMADZU HMV 2T.

Temperature: $24{ }^{0} \mathrm{C}$, (reference temp. $23 \pm 5^{0} \mathrm{C}$ ); humidity $50 \%$.

For optical microscopy test. Devices used: Microscope Olympus GX51, Reagent: Nital 2\%

Temperature: $22{ }^{0} \mathrm{C}$, (reference temp. $23 \pm 5^{\circ} \mathrm{C}$ ); humidity $52 \%$ :

Based on these analyses, the following results were achieved: for circular drawn bars (Material - OLC45) shown in Tab.1.

A light increase of hardness is observed, from center towards peripheral areas. Maximum hardness was determined app. $300 \mu \mathrm{m}$ away from the bar side.

Data regarding specific measurement conditions:

Force applied: 1,961 N; measurement time: 10 seconds.

Measurements were made to test the values of microhardness of bodies in the samples of carbon steel, plastically deformed through drawing (Dumitrescu, T. 2004). Five measurements were carried out for each of the various areas of the test sample (circular bar with $40 \mathrm{~mm}$ diameter), as follows: central area of the bar $(\mathrm{C})$, peripheral area located app. $150 \mu \mathrm{m}$ away from the lateral surface (150), area located $300 \mu \mathrm{m}$ away from the lateral surface (300), area located $1 \mathrm{~mm}$ away from the lateral surface (1), area located $2 \mathrm{~mm}$ away from the lateral surface (2), area located $5 \mathrm{~mm}$ away from the lateral surface (5), area located from the lateral surface $7 \mathrm{~mm}$ (7). Readings were made in line, with fixed deviations.

\begin{tabular}{|c|c|c|}
\hline Area measured & Values determined, HV0,2 & $\begin{array}{c}\text { Average } \\
\text { value }\end{array}$ \\
\hline Center (C) & $252,257,249,258,256$ & 254 \\
\hline Area 7 & $264,257,259,259,263$ & 260 \\
\hline Area 5 & $255,271,262,264,265$ & 263 \\
\hline Area 2 & $265,260,261,273,262$ & 264 \\
\hline Area 1 & $262,264,261,265,262$ & 263 \\
\hline Area 300 & $281,278,263,285,267$ & 275 \\
\hline Area 150 & $255,251,260,252,257$ & 255 \\
\hline
\end{tabular}

Tab. 1. Results of hardness test HV0,2

Peripheral area (Fig.1a, 1b)

Finished grains compared with those in central areas, oriented on the plastic deformation direction.

Structure: Lamellar pearlite and ferrite, with rare intergrain inclusions. We notice the presence of a sloping type discontinuity of deformed material, with surface fragmentation (Dumitrescu\&Vasilescu,1999)

Basic material - Fig. 1c), 1d).

The central area of the sample, with large grains, with a basic matrix containing lamellar pearlite (dark brown shades) and ferrite (polyhedral grains, white).

For cold drawn rectangular bar (Material - OLC15). An increase on the lateral compared to the central area only 


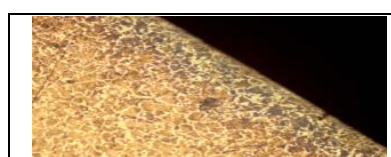

a) $200 x$

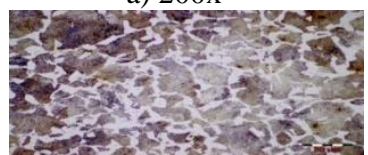

c) $500 x$

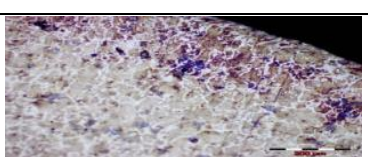

b) $100 x$

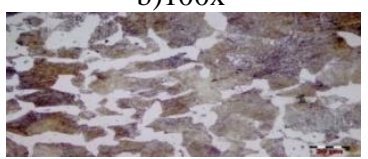

d) $1000 x$
Fig. 1. Microscopic examination of cold drawn circular bar

for the sample 20x12. The hardness values were determined for a distance of app. $100 \mu \mathrm{m}$ away from the lateral side of the bar.

We noticed that, on gross grains, the micro-hardness was lower compared to at determined on the assembly of small grains. In the lateral deformation area, the micro-hardness prints are asymmetrical, having a larger value diagonal on the direction of plastic deformation.

Data regarding specific measurement conditions:

Force applied: $1,961 \mathrm{~N}$; measurement time: 10 seconds

Measurements were made to test the values of microhardness of bodies in the samples of carbon steel, plastically deformed through drawing (Dumitrescu, 1997).

Five measurements were carried out for each of the various areas of the test sample (rectangular bar with $40 \mathrm{~mm}$ diameter), as follows: central area (C), peripheral area located app. $100 \mu \mathrm{m}$ away from the side surface (1), peripheral area located app. $100 \mu \mathrm{m}$ away from the side in the opposite direction (2), area located app. $100 \mu \mathrm{m}$ away from the side with a width of 20 $\mathrm{mm}$. up (3), area located app. $100 \mu \mathrm{m}$ away from the side with a width of $20 \mathrm{~mm}$ down (4). Readings were made in line, with fixed deviations.

\begin{tabular}{|l|c|c|}
\hline Measurement area & Measured values, HV0,2 & Average val. \\
\hline Center C & $169,165,174,168,171$ & 169 \\
\hline Area 1 & $166,168,168,187,174$ & 173 \\
\hline Area 2 & $167,173,177,177,170$ & 173 \\
\hline $20 \mathrm{~mm}$ area up (3) & $165,173,158,160,175$ & 166 \\
\hline $20 \mathrm{~mm}$ area down4) & $169,161,166,163,161$ & 164 \\
\hline
\end{tabular}

Tab. 2. Results of the hardness test HV0,2 (sample 20x12)

Peripheral area (Fig.2a, 2b, 2c).

Gross grains compared with grains in central areas, oriented on the direction of plastic deformation.

Structure: ferrite and pearlite with globular morphology due to plastic deformation, with inclusions. The structure includes gross and elongated grains (ill. $2.2-\mathrm{a}$, ill. 2.2. $-\mathrm{c}$ ) respectively re-crystallized ferrite gross grains (ill. $2.2-\mathrm{a}$ ). We notice the presence of a sloping type discontinuity of deformed material (ill. $2.2-$ c), micro-cracks and surface fragmentation (ill. $2.2-$ b) in corner area. In peripheral areas the ferrite grains are found in much larger concentrations compared to the central areas, while the pearlite has fragmented and distributed as fine particles chained on grain borders (Maltev, 1996).

Basic material (Fig. 2d, 2e).

The central area of the sample, with large grains, with a basic matrix containing ferrite (polyhedral grains, white) and sphere-shaped lamellas of pearlite (dark brown shades).

\section{CONCLUSION}

The precast products tested were hot laminated steel bars and platbands (not cold drawn) OLC45 and OLC15, where the preparation of outer surfaces (removal of iron oxides - iron scales, resulted from lamination) was made with bead blasting.

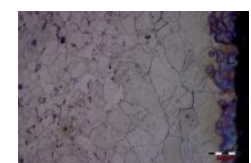

a) $500 x$

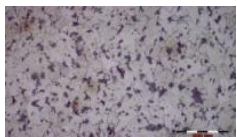

d) $200 x$

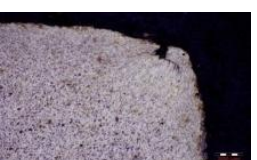

b) $100 x$

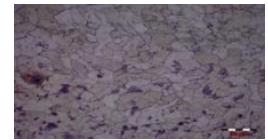

e) $500 x$

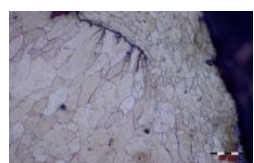

c) $200 x$
Fig. 2. Microscopic examination of cold drawn platband

The beads used were obtained by cutting from unhardened soft wire OL37, of particles $\varnothing 2 X 4.5 \mathrm{~mm}$. Beads velocity was $10 \mathrm{~m} / \mathrm{s}$.

In case of cold drawn bars, the following issues were noticed:

- as for the hardness $\left(\mathrm{HV}_{0.2}\right)$, an increase was noticed from center towards peripheral areas, maximum hardness being measured app. $300 \mu \mathrm{m}$ away from the bar's side surface;

- as for the microstructure, in peripheral areas we noticed finished grains compared to those in central areas, oriented on the direction of plastic deformation;

- structurally, in both areas we noticed lamellar pearlite and ferrite, with rare intergrain inclusions in peripheral areas, and in central area with ferrite in white polyhedral grains;

- we notice the presence of a sloping type discontinuity of deformed material, with surface fragmentation.

In case of cold drawn platbands, with various reductions, we noticed the following:

- as for the hardness $\left(\mathrm{HV}_{0.2}\right)$, in most cases we've seen a slight increase in central areas compared to peripheral areas, and in one sample (20x12) a lateral hardness increase compared to the central area;

- as for the microstructure, in peripheral areas we noticed gross grains compared with those in central areas, oriented on the direction of plastic deformation;

- structurally, in both areas we meet ferrite and lamellar pearlite with globular morphology due to plastic deformation and inclusions in peripheral areas, and in central areas ferrite and pearlite with sphere-shaped lamellas;

- we noticed the presence of a sloping type discontinuity of deformed material, micro-cracks and surface fragmentation in corner areas.

\section{ACKNOWLEDGEMENTS}

We want to specify that the results included in this paper were obtained in the frame of Romanian National Program of Research, "Innovation", partnership between S.C.Industrial Proiect SRL and University "Politehnica" of Bucharest.

Special thanks to Ms. Professor Doctor Ionelia Voiculescu.

\section{REFERENCES}

Dumitrescu, T., (1997). Research regarding the modification process of steels, Anais do 80 Encontro Nacional do Sociedade Portuguesa de Materiais Procedings of the $8^{*}$ National

Dumitrescu, T. (2004). Researches regarding influence of modifying the microstructure, macrostructure and plastic deformation capacity of steels, Metalurgia Magazine no. 5/2004, Scientific Publishing FMR

Dumitrescu, T.; Vasilescu, E. (1999). Iron-carbon alloy, micro structural constituents, Macarie Publishing, Târgovişte

Maltev, M.V. (1996). Modification of metals and alloys structure, Bucharest Technical Publishing

Oprea, F. (1978). Metallurgical process theory, Didactic and Pedagogical Publishing, Bucharest ISBN 973-98904-8-2 